\title{
I
}

\section{DE INTELECTUAIS AO PRECARIADO: PARA ONDE VÃO OS PROFESSORES E O ENSINO DE HISTÓRIA?*}

\author{
Antonio Simplicio de Almeida Neto \\ Paulo Eduardo Dias de Mello
}

Sabe-se que os enfrentamentos no campo do ensino de História ${ }^{1}$ são inúmeros e cotidianos, e têm crescido de modo proporcional ao aumento das desigualdades e ao desrespeito às diferenças de gênero, étnico-raciais, de sexualidade, religiosas, regionais. Alguns desses enfrentamentos parecem retornar de obscuros porões, às vezes com novas roupagens, outras à marretadas, o que nos obriga, professores de História, a reviver debates que se constituem como verdadeira afronta, que já foram feitos nos anos 1980 e, talvez iludidos com o avanço das agendas da inclusão e da democratização, supúnhamos superados. Nesse quadro, entre o passado idílico e o presente infausto, poderíamos supor que o ensino de história ocuparia posição central. No entanto, e paradoxalmente, parece que vem se esvanecendo, se dissipando, tornando-se descartável, desnecessário. E enquanto se desvanece, outra moldura se impõe repondo carcomidos discursos, teses falaciosas, distorções deliberadas, negações obtusas e censuras.

No conhecido texto "Entre a memória e a história: a problemática dos lugares", escrito na década de 1980, o historiador francês Pierre Nora provocou: "Fala-se tanto de memória, porque ela não existe mais". Parafraseando Nora, no atual cenário brasileiro, somos levados a também provocar: Fala-se tanto em ensino de história, porque ele não existe mais. Não existe mais ou estaria com os dias contados.

Vejamos algumas peças do mosaico que compõe essa cena.

*DOI- 10.29388/978-65-86678-50-5-0-f.25-40

${ }^{1}$ Utilizaremos "História" para referir à disciplina escolar e "história" para a área. 


\section{Celebrando a história e o ensino de História}

No dia 18/agosto/2020 foi publicada no Diário Oficial da União a lei 14.038 que regulamenta a profissão de historiador, segundo a qual é considerado "historiador", entre outros, quem tem diploma de curso superior, mestrado ou doutorado em história. Entre as atribuições profissionais dos historiadores, o texto prevê, dentre outras atividades, o magistério da disciplina de história nas escolas de ensino fundamental e médio. Destaque-se a palavra "disciplina". Quando da aprovação da referida lei houve justas e efusivas comemorações na comunidade dos historiadores, com artigos, manifestações públicas, debates, lives e likes. Nunca se falou tanto em história, ensino de história e historiadores. Naquela ocasião fomos tomados por um estranho e lúgubre sentimento de estarmos comemorando à beira de uma sepultura. Especialmente no que se refere à parcela de profissionais-historiadores que atua na educação básica.

Em agosto/2020, um colega ${ }^{2}$ compartilhou, generosamente, na lista de e-mails do GTEH da ANPUH-Nacional, um levantamento feito por seu grupo de pesquisa Roda de Histórias ${ }^{3}$, das publicações sobre ensino de história, segundo o qual, nas décadas de 1980/90 foram publicados 5 dossiês sobre ensino de história em Revistas Acadêmicas; nos anos 2000, 18 dossiês; e nos anos 2010, 68 dossiês. Percebe-se um crescimento vertiginoso dessas publicações nos últimos 40 anos. Isso sem considerarmos a publicação de artigos avulsos, capítulos de livros e livros autorais. Nunca se falou e publicou tanto em ensino de história.

Nesse mesmo período também tivemos a expansão da participação dos pesquisadores e professores do ensino de história em eventos acadêmicos nacionais e internacionais, como os da ANPUH (nacional e regionais), com Simpósios Temáticos específicos e Mesas Redondas sobre o tema. Também foram criados eventos específicos sobre o ensino de história, como o Perspectivas do Ensino de História (cuja $1^{\text {a }}$ edição ocorreu em 1988, na FEUSP) e o Encontro Nacional dos Pesquisadores do Ensino de História - ENPEH (cujo 1º evento ocorreu em 1993 na UFU). Em 2006 chegou a ser criada uma associação específica dos pesquisadores de ensino de história, a Associação Brasileira de Ensino de História - ABEH. Em outubro/2019 ocorreu em Salvador, Bahia, o $1^{\circ}$ Congresso Nacional do ProfHistória. Nunca nos reunimos tanto para falar sobre ensino de história.

Também nesse período, os últimos 40 anos, observa-se um crescente número de pesquisas de mestrado e doutorado sobre ensino de história, tanto

\footnotetext{
${ }^{2}$ Prof. Leandro Almeida da Universidade Federal Recôncavo Baiano (Cachoeira, BA)

${ }^{3}$ Disponível em: < https://www.rodahistorias.pro.br/revistas-dossies-ensino-historia $>$. Acesso em: 06 out. 2020 .
} 
em Programas de Pós-Graduação de História, como nos de Educação. Nessa esteira, em 2014, foi criado o ProfHistória ${ }^{4}$, um mestrado profissional em ensino de história, stricto sensu, em rede, voltado para professores de história em exercício profissional. Em 2014 havia 6 Instituições de Ensino Superior - IES nessa rede, em 2016 ela se ampliou para 24 IEs e em 2020 passamos para 39 IEs, em todas as regiões do país. No último processo seletivo para as turmas de 2020 houve 3.553 candidatos em todo o território nacional, para 711 vagas, o que dá uma média nacional de 5 candidatos/vaga. Enfim, nunca se falou e se pesquisou tanto em ensino de história.

\section{No reino encantado da BNCC-EM}

Mas, enquanto isso... no reino, não tão distante da Base Nacional Comum Curricular do Ensino Médio, ninguém mais fala em ensino de história. Por ato legal proposto no Governo de Michel Temer e com apoio dos parlamentares, a disciplina de História foi ceifada de seu lugar obrigatório no currículo do Ensino Médio passando a figurar apenas como um mero componente curricular, dentre outros, diluídos insipidamente na área de Ciências Humanas e Sociais Aplicadas. A referida lei ${ }^{\circ}$ 13.415, de 16 de fevereiro de 2017, que realizou a Conversão da Medida Provisória n ${ }^{\circ} 746$, de 2016, urdida com sôfrega celeridade dos reformadores empresariais e suas fundações precipitou-se ávida sobre o campo educacional para alardear e implantar o mais "Novo Ensino Médio".

Na sequência, em 14 de dezembro de 2018, o então ministro da Educação, Rossieli Soares, homologou o documento da Base Nacional Comum Curricular para a etapa do Ensino Médio. O anúncio pomposo e oficial nos dava conta de que, enfim, o Brasil teria uma "Base" com todas as aprendizagens previstas para a Educação Básica. No documento a área de Ciências Humanas e Sociais Aplicadas, que aparece integrada por Filosofia, Geografia, História e Sociologia, está organizada de modo a tematizar e problematizar algumas categorias tomadas como autoexplicativas e consideradas fundamentais à formação dos estudantes: Tempo e Espaço; Territórios e Fronteiras; Indivíduo, Natureza, Sociedade, Cultura e Ética e Política e Trabalho.

Preservada no Ensino Fundamental como disciplina, ainda que numa versão controversa, no Ensino Médio a História padece de um rebaixamento epistemológico-curricular e tem uma presença algo fantasmagórica, abstrata e

\footnotetext{
${ }^{4}$ Disponível em: < https://profhistoria.ufri.br/>.
} 
conceitual. São os novos tempos anunciados da superação da fragmentação disciplinar dos conteúdos. Tempos de flexibilidade exigem novos termos. Assim, reza o mantra do "novo", supere-se a rígida fixidez cadavérica das disciplinas, adote-se a flexibilidade do termo componente curricular, que facilita a interdisciplinaridade ${ }^{5}$ e a invenção de formas de estudos ou práticas que envolvam conteúdos não convencionais. Apenas as disciplinas Língua Portuguesa e Matemática são referidas nominalmente, afinal algo precisa ser conservado nesse mar de novidades.

A História inserida na área mais geral denominada "Ciências humanas e Sociais aplicadas", empresta seu sabor exótico à geleia geral que une as coirmãs disciplinares. Mas, se a especificidade do conhecimento histórico foi diluída porque haveria de existir a obrigatoriedade da presença daquele profissional, agora reconhecido por lei: É necessário um Historiador para trabalhar com a área de Ciências Humanas? Ou poderia ser um professor coringa Sociólogo, Geógrafo ou Filósofo? Será que o professor de História no Ensino Médio se tornará uma espécie de rei sem reino ou, se preferirem, um profissional sem profissão? É certo que o novo desenho curricular da BNCC não impede que haja a disciplina História, que até pode ser uma das opções das possíveis "unidades curriculares" que comporão os novíssimos currículos, a depender do traçado elaborado pelas secretarias estaduais de educação para o Ensino Médio.

Como se sabe, a BNCC está sendo desdobrada nos estados da federação. Cada sistema de ensino precisa elaborar seu próprio documento curricular a partir do documento nacional. São Paulo deu a largada desse processo no Ensino Médio. Lembremos que no caso do estado de São Paulo, o atual secretário de educação, Rossieli Soares da Silva, o mesmo que foi ministro de educação no final do governo Temer e elaborou o documento Guia de Implementação do Novo Ensino Médio (2018), que propunha orientar os estados sobre como implementar os chamados itinerários formativos, apresentou o modelo curricular que foi recentemente adotado em São Paulo em anúncio efusivo ${ }^{7}$, como o primeiro estado a implementar a BNCC-EM, e que poderá ser espelhado em outras unidades da federação.

\footnotetext{
${ }^{5}$ Nada contra a interdisciplinaridade e o trabalho com projetos. No entanto, não há interdisciplinaridade sem disciplinas. Não há projetos consistentes sem diálogos sobre conceitos que estão vinculados a campos disciplinares e possuem, eles próprios, historicidade.

${ }^{6}$ Disponível em: < http://novoensinomedio.mec.gov.br/\#!/guia >. Acesso em: 06 out. 2020.

${ }^{7}$ São Paulo é o primeiro estado do Brasil e adotar o currículo do Ensino Médio in <https://www.saopaulo.sp.gov.br/ultimas-noticias/sp-e-o-primeiro-estado-do-brasil-a-aprovar-ocurriculo-do-ensino-medio/\#: : :text=Estrutura $\% 20 \mathrm{do}_{0} \% 20$ curr $\% \mathrm{C} 3 \% \mathrm{ADculo}, \mathrm{s} \% \mathrm{C} 3 \% \mathrm{~A} 3 \mathrm{O}$ \%20referentes $\% 20$ aos $\% 20$ itiner $\%$ C $3 \%$ A 1 rios $\% 20$ formativos $>$. Acesso em: 06 out.2020.
} 
Segundo informação do referido site da SEE-SP sobre o Novo Ensino Médio, haveria uma oferta de "formação geral básica" na qual os "estudantes terão os componentes curriculares divididos em áreas de conhecimento". É sempre bom lembrar que componente curricular possui um status diferente de disciplina escolar e que a história está dentro da área de Ciências Humanas e Sociais Aplicadas. O anunciado itinerário formativo seria feito em função das escolhas dos estudantes, considerando uma idealização curricular quimérica neoliberal denominada "projeto de vida", e pode ser "uma ou duas áreas de conhecimento da formação geral para aprofundar seus estudos, ou ainda, a formação técnica e profissional para se aprofundar”. Porém, no mundo objetivo, como previsto no Guia de Implementação do Novo Ensino Médio, o projeto de vida de cada estudante deverá ser ajustado à realidade: às possibilidades das escolas e das redes, a estrutura física das escolas, a formação dos professores daquela escola, aos interesses da comunidade e dos pais. Não à toa no último dia 29/agosto, um subsecretário de ensino profissionalizante da Secretaria de Desenvolvimento Econômico do Estado de São Paulo, publicou um longo artigo na Folha de São Paulo intitulado 'Educação não é um fim em si mesma e deve se aproximar do mercado de trabalho - maior interação propiciada pelo Novo Ensino Médio ampliará o horizonte de carreiras para jovens de baixa renda". Nesse artigo o subsecretário defende sem meias palavras que "escolas, governos e até setor produtivo se unam para garantir que a juventude esteja bem equipada para buscar empregos formais ou trabalhar como empreendedora autônoma'. Para tanto deve-se aproveitar o que ele chama de janela de oportunidades do Novo Ensino Médio, que abre a possibilidade de oferta de formação técnica e profissional, particularmente aos mais pobres "que precisarão gerar renda cedo". E essa situação, segundo ele, torna-se mais oportuna pelo "mercado de trabalho mais arisco no pós-pandemia". O texto parece ser uma versão educacional do "vamos passar a boiada" proclamada pelo ministro do Meio Ambiente. Para os de baixa renda, a educação deve preparar para competir por empregos no mercado de trabalho e, na falta destes, forjar empreendedores individuais.

Enfim, tudo leva a crer que o destino dos alunos da maior parte das escolas públicas já está traçado (mesmo que se elaborem projetos de vida) e o percurso formativo preferencial será mesmo a formação técnica e profissionalizante, no qual o conhecimento histórico é totalmente dispensável. Temos, portanto, aqui, uma dupla cilada para o ensino de história e o profissional que nele

\footnotetext{
8 "O Novo Ensino Médio torna obrigatório que o projeto de vida dos estudantes seja desenvolvido em todas as escolas." Como consta em: < http://novoensinomedio.mec.gov.br/\#!/pagina-inicial $>$. Acesso em: 07 out. 2020.
} 
atua: 1. A disciplina escolar História está diluída numa área generalizante, que existe como uma espécie de agrupamento burocraticamente definido de ciências afins, como vemos na classificação dos órgãos de fomento à pesquisa. Ainda que recentemente tenham surgido alguns cursos superiores de Ciências Humanas, eles não formam, a rigor, cientistas em humanas. Não há, portanto, uma categoria de pesquisadores com essa denominação genérica, mas historiadores, geógrafos, sociólogos, filósofos, antropólogos. 2. Essa área poderá ficar de fora dos itinerários formativos, caso prevaleça, por exemplo, o percurso técnico profissional, como apregoa um subsecretário de São Paulo.

\section{BNC-FP: a peça que faltava}

O golpe maior na História (na área e na disciplina) vem com a Base Nacional Comum de Formação de Professores, que foi definida pelas Diretrizes $\mathrm{CNE} n^{\circ} 2$ de 20/dezembro/2019. Golpe é um termo político que designa o ato de força que impõe uma mudança de regime. O termo aqui é usado para denominar o processo de imposição de uma nova Diretriz para a formação de professores às Universidades, feito à revelia da participação das entidades representativas das instituições de formação de professores e das próprias IEs, que rompe e revoga a Diretriz elaborada em 2015, o que se configura como uma mudança forçada no regime de formação dos professores. Temos então um golpe, nas instituições universitárias, que se desdobra, que é processual, que ainda está em curso.

Alguns aspectos merecem ser sublinhados. Um diz respeito aos sujeitos que desferem o golpe (reservando ao gesto ares, democráticos e de legitimidade): os reformadores da educação, suas fundações e seus intelectuais orgânicos. Outro concerne à sua articulação com as reformas educacionais em curso, que gravitam em torno do currículo (BNCC + Reforma do Ensino Médio + Base Nacional Curricular-Formação de Professores- BNC- FP).

Vejamos as novas Diretrizes travestidas de BNC-FP. Elas não são mais diretrizes no sentido de linhas gerais a partir das quais um plano é traçado, ou num sentido figurado, esboços de planos a serem ainda delineados. Aqui as novas "Diretrizes" assumem outra conotação: elas definem regras e procedimentos para todos os cursos de formação de professores (entre eles, obviamente, o de História) e afirma que esses cursos deverão estar "em consonância com as aprendizagens que são prescritas na BNCC" da educação básica. Ou seja, trata-se de transformar os cursos de formação de professores em cursos para formar apli- 
cadores da BNCC, ou seja, cursos de treinamento. Pretende-se que os cursos promovam o adestramento docente para uma futura aplicação de um currículo específico, a BNCC, o que resultaria em melhorias na Educação Básica, entendidas nessa concepção como melhores resultados da Educação Básica nos exames padronizados de larga escala. Nessa linha fordista de formação e transmissão os formadores (historiadores e pesquisadores de ensino de História) formam professores da Educação Básica dotados de competências profissionais para o exercício da BNCC em sala de aula. Exercício cuja eficácia e eficiência será medida pelos exames. Nesse cenário, que remete ao icônico Tempos Modernos (1936) da cinematografia chapliniana, o formador forma o professor, que forma o estudante na esteira rolante da BNCC.

Não por acaso a prefeitura do Rio de Janeiro, sob a gestão de Eduardo Paes (PSDB, 2009-2016), ilustrou uma propaganda de seu governo com uma imagem que oscila entre a desfaçatez e a desmedida. A peça publicitária ${ }^{9}$ veiculada em dezembro de 2014 visava divulgar a criação da, assim denominada, Fábrica de Escolas do Amanhã, uma unidade que seria responsável pela construção de estruturas pré-moldadas, armazenamento e distribuição de materiais para a rede carioca de ensino. A montagem fotográfica trazia, em fundo branco, uma esteira rolante de linha de montagem prateada, reluzente, em ambiente asséptico, sobre a qual deslizam três carteiras escolares de estrutura branca e tampos azuis, novas, ocupadas por duas crianças negras e uma branca, impecavelmente uniformizadas, absortas pelos deveres escolares enquanto a linha de produção fabril opera automática e mecanicamente seu curso. Sobre a fotografia lemos, em caixa alta: "NOSSA LINHA DE PRODUÇÃO É SIMPLES: CONSTRUÍMOS ESCOLAS, FORMAMOS CIDADÃOS E CRIAMOS FUTUROS”.

A relação educação/mercadoria e estudante/produto é imediata e inevitável. A composição fotográfica evoca a representação eternizada pelo filme Pink Floyd - The Wall (1982), que, em dado momento, ao som da música Another Brick In The Wall, estudantes ingressam num modelo escolar fabril, deslizam numa esteira rolante, sentados em carteiras escolares que resulta, ao fim do processo, em carne moída, em que a criatividade e a individualidade são destruídas.

Ato falho, ou nem tanto, a propaganda da gestão Paes capta perfeitamente certo zeitgeist escolar brasileiro, em que o modelo fabril e as técnicas gerencialistas são elevadas à condição de solução educacional.

A ascensão dessas concepções marca um processo de ruptura lenta e gradual com outras mais progressistas e humanistas conquistadas e consagradas

${ }^{9}$ Disponível em: < $\quad$ https://educacao.uol.com.br/noticias/2014/12/09/prefeitura-do-riocompara-escola-a-fabrica-e-gera-criticas-no-facebook.htm >. Acesso em: 31 out. 2020. 
na constituição de 1988 e reafirmadas na LDB de 1996. Dentre os princípios que deveriam reger o ensino, o texto constitucional estabeleceu o princípio da igualdade de condições para o acesso e permanência na escola, além de prever garantia de padrão de qualidade e apontar o princípio da gestão democrática do ensino público. A elaboração de um projeto ou proposta pedagógica da escola, com participação dos docentes, tornou-se uma exigência legal para todas as escolas do país, com a promulgação da Lei de Diretrizes e Bases da Educação Nacional, a Lei 9394/96. Com a LDB, portanto, o projeto político-pedagógico se tornou um elemento constitutivo da autonomia da escola e, ao mesmo tempo, expressão e elemento de construção de relações democráticas em seu interior.

Se, por um lado, a legislação educacional revelou avanços importantes no campo democrático, por outro lado, foi também na década de 1990 que as discussões sobre o planejamento e a gestão educacional foram progressivamente afetadas pela adoção dos pressupostos do neoliberalismo. Tais ideias geraram propostas de novos padrões de regulação estatal, que se explicitaram e ainda reverberam na expressão "Estado Mínimo". No campo da gestão empresarial surgiram as concepções baseadas no conceito de "qualidade total", um modelo que pregava eficiência absoluta no controle dos processos produtivos. Aos poucos, a ofensiva neoliberal introduziu-se no campo educacional, a concepção de Qualidade Total, baseada na melhoria dos processos gerenciais e na satisfação do cliente, ganhou forte adesão como modelo de gestão mais apropriado para resolver os problemas educacionais. Nessa concepção a escola passou a ser vista como uma empresa prestadora de serviços cuja "mercadoria" a ser oferecida é a educação, e a comunidade escolar, os pais e alunos são considerados seus "clientes”. Os profissionais da escola são os 'colaboradores' que devem ser competitivos e produtivos visando atender às demandas de sua clientela, especialmente combatendo os "desperdícios" provocados pelos altos índices de evasão e reprovação dos alunos, assegurando resultados de aprendizagem em exames de testes padronizados.

Tal concepção, construída paulatinamente, se espraiou no campo educacional, e teve sua implementação acelerada no contexto do Golpe de 2016. Foi nesse contexto que as discussões sobre reformulações da Educação Básica, o currículo e o "novo" Ensino Médio, acabaram sendo ocupados e redefinidos por esse prisma gerencialista focado em resultados. E foi sob esse impulso e concepções que se pretendeu reformar a Educação Básica e dar novo sentido à formação de professores. BNCC e BNC-FP estão sob influência direta de processos ligados a uma concepção engendrada na lógica dos reformadores empresariais e seus modelos de gestão das mudanças desejadas. Podemos perceber di- 
ferentes aspectos constantes no documento que redefine a formação de professores que revelam essas concepções tecnocráticas e gerencialistas. Dentre eles destacaremos dois que consideramos centrais no debate por suas implicações na formação dos professores de história e no ensino dessa disciplina na educação básica: a distribuição da carga horária no currículo e a concepção de Prática Pedagógica que o orienta.

Nas Diretrizes a carga horária mínima do curso será mantida em 3200 horas. Mas ocorre uma redistribuição dela em 3 grupos sendo: Grupo 1) 800 horas para conhecimentos científicos, educacionais e pedagógicos que fundamentam a educação (comuns a todas as licenciaturas) - Conteúdos de Psicologia, Fundamentos da Educação, Gestão, Políticas Educacionais, História da Educação, Didática, Currículo, Legislação, Metodologias e Práticas de Ensino, Avaliação de desempenho, Cultura da escola, Mediação de Conflitos; Grupo 2) 1600 horas, para a aprendizagem dos conteúdos específicos das áreas, componentes, unidades temáticas e objetos de conhecimento da BNCC, e para o domínio pedagógico desses conteúdos; e Grupo 3) 800 horas de Prática Pedagógica distribuídas entre Estágio Supervisionado, e mais 400 h para a prática dos componentes curriculares dos Grupos 1 e 2 .

Vemos, portanto, uma considerável ampliação da carga horária das disciplinas prático-pedagógicas na formação dos professores, enquanto a das disciplinas específicas de História serão diminuídas. De saída temos várias implicações dessa forma de distribuição e seus impactos no currículo atual de formação. A aparente e simples divisão de $50 \%$ para a área pedagógica e prática e $50 \%$ para área específica revela um falso equilíbrio. Na realidade cai por terra a ideia alimentada, desde pelo menos os anos 1980, de formar um professor de História com sólida formação historiográfica, já que a carga horária destinada aos conhecimentos específicos de História será reduzida para ampliar a carga da área pedagógica. Essa pedagogização (entendida como ampliação de carga horária) da formação contribui para consolidar a consagrada, e tão criticada, separação entre a formação do historiador (pesquisador) e do professor de História. O primeiro (bacharel/pesquisador) aparentemente terá uma formação mais sólida na área e estará voltado à pesquisa e o segundo (licenciado/professor) terá apenas uma formação básica que lhe permita ser professor, e quiçá pesquisador na área de ensino de História.

Se considerarmos que os estudantes dos cursos de graduação em História buscam, em sua esmagadora maioria, a Licenciatura, ainda que nem todos sigam a carreira do magistério e prefiram a pesquisa stricto sensu, isso vai alterar profundamente a organização dos cursos, atingindo a todos: os graduandos, os 
professores que lidam diretamente com o ensino de história e também os professores das áreas específicas como História Medieval, História Antiga, História do Brasil, etc. Teremos ainda muitas disputas internas aos cursos de formação de História entre as áreas específicas da História, a área de Ensino de História e a área Pedagógica. Que áreas da História serão aquinhoadas com mais espaço no novo currículo? Quem cederá espaço? Quem ganhará? Mesmo que alguns possam apostar que esta seja uma oportunidade de superar o quadripartismo histórico e redesenhar o currículo ${ }^{10}$, não importa, o desenho tem uma moldura rígida e limitada em termos de carga horária vinculada aos estudos sobre a produção do conhecimento histórico em todas suas subáreas.

Vale sublinhar também como essas novas Diretrizes de Formação de Professores concebem as Práticas Pedagógicas. No documento elas são pensadas como atividades que se desenvolvem desde o primeiro ano do curso de formação de professores e devem ocorrer através dos estudos e práticas previstos nos componentes curriculares, assim distribuídas: 400 (quatrocentas) horas de estágio supervisionado, em ambiente de ensino e aprendizagem; e 400 horas, ao longo do curso, entre os temas dos Grupos 1 e 2. Esses temas também estão pré-definidos. No Grupo 1, por exemplo, são detalhadas ao todo 13 temáticas, dentre as quais: a) os currículos e seus marcos legais (LDB, devendo ser destacado o art. 26-A; b) Diretrizes Curriculares Nacionais; BNCC: introdução, fundamentos e estrutura; e currículos estaduais, municipais e/ou da escola em que trabalha); b) a didática e seus fundamentos; c) metodologias, práticas de ensino ou didáticas específicas dos conteúdos a serem ensinados; d) conhecimento da cultura da escola, o que pode facilitar a mediação dos conflitos; etc. Para o Grupo 2 que compreende o aprofundamento de estudos na etapa e/ou no componente curricular ou área de conhecimento, a carga horária de 1.600 horas há um detalhamento assustador que inclui, por exemplo, até o "conhecimento da Matemática para instrumentalizar as atividades de conhecimento, produção, interpretação e uso das estatísticas e indicadores educacionais". Esse exemplo, revela como as preocupações das Diretrizes estão diretamente vinculados aos indicadores de sucesso e performance educacional, introjetando a responsabilização docente para a melhoria de indicadores na própria formação.

As novas Diretrizes produzem o rebaixamento do docente de História em seu estatuto de intelectual, para transformá-lo em técnico a serviço de um

\footnotetext{
${ }^{10}$ Veja-se a respeito a tese de FERREIRA (2015). A autora analisou 96 Projetos Pedagógicos de Curso Licenciatura em História das universidades federais e estaduais brasileiras e os depoimentos de formadores de professores de História envolvidos na mudança curricular proposta em 2002 em seus cursos e/ou na implantação dos novos currículos.
} 
currículo programado, amarrado a um ensino estruturado por meio de materiais didáticos e novas plataformas digitais. Destarte, a dimensão utópica (ALMEIDA NETO, 2011) que permeava as representações sobre o papel e função social da docência cedem espaço para as formulações pragmáticas e praticistas sobre a formação e o fazer docente na disciplina de História, onde ser docente é simplesmente produzir resultados mensuráveis e alcançar metas de aprendizagem.

\section{Considerações finais}

O cenário das políticas em curso reserva outros elementos importantes que não podem ser ignorados. Vivemos tempos de intensos ataques ao serviço público, particularmente à educação pública e à profissão docente, com estigmatização, censura e desqualificação. Por trás desta estratégia de corrosão do apoio social ao professor e da erosão de sua imagem há o propósito de convertê-lo em mero técnico educacional, um reles aplicador de currículos prescritos, reprodutor de materiais didáticos que definem passo a passo sua aula. No limite, pensando no processo de longa duração da formação e consolidação da profissão docente o que assistimos é um processo de ruptura de seu status como intelectual, como servidor público, para torná-lo simples funcionário descartável de um modelo de educação pública (talvez ainda) de gerenciamento privado, numa lógica corporativa que valoriza performance e resultados. É o fim do docente como intelectual. É o fim do docente como funcionário público concursado, protegido das ingerências políticas. É a imposição do professor precariado, no sentido dado pelo sociólogo inglês Guy Sterling (2014), daqueles profissionais sem estabilidade, com baixos salários, sem carreira, sem horizontes de expectativas. Nesse sentido entendemos que as novas Diretrizes de Formação de Professores se alinham e contribuem para um processo mais largo de precarização e uberização da profissão docente.

Evidentemente, não se trata de ignorar o fato de que são necessárias mudanças nos cursos de formação. A questão é que qualquer reforma dessa amplitude não poderia atropelar a autonomia universitária e as características locais dos cursos, unificando a formação precária em nível nacional. Ademais, esse processo já vinha sendo construído em várias instituições desde 2002 (data da primeira resolução que alterou os cursos de formação de professores pósLDB-1996), e ganhou novo impulso em 2015 com uma nova Resolução que ampliava a necessidade de incluir temáticas da diversidade e pensava a profissão 
docente como um todo complexo. A atual BNC-FP gestada no contexto e desdobramento do Golpe de 2016 é mais um lance desse processo que se trama e se desenrola no campo da educação para acelerar a mercantilização com base na precarização.

Assim, se representássemos o campo do Ensino de História como uma árvore, poderíamos verificar que nas últimas décadas ela tem se mostrado frondosa, apesar de tudo. Ela ainda possui raízes profundas na Educação Básica desde o século XIX, sua seiva circula pelo Ensino Fundamental, Ensino Médio e Superior. Suas raízes também se nutrem no solo da história, de uma produção historiográfica cada vez mais crítica e próspera. Seus ramos no ensino superior cresceram significativamente. Na graduação, os cursos se multiplicaram. Seus eventos e publicações revelam uma produção pujante. Novos ramos florescem com programas de pós-graduação que acolhem professores da educação básica. Respiramos promessas de novos frutos, num ciclo que revitaliza raízes, ramos, folhas e frutos. Esse quadro quase idílico somado ao reconhecimento da profissão de historiador, projeta para quem labuta na área o melhor dos mundos: enraizamento firme na educação básica, fortalecimento da pesquisa cada vez mais articulada às raízes, pluralidade de frutos.

Mas, se ampliarmos nosso olhar da árvore para a floresta veremos que o quadro reserva graves ameaças. Agentes obscurantistas, de motosserra em punho, vociferam contra a ciência, dispostos a negá-la e abatê-la e tecnocratas cortam suas raízes e verbas. $\mathrm{Na}$ educação básica pública os programas curriculares voltam-se ao treinamento de estudantes para os sistemas de avaliação, tornada a grande e única finalidade da escola. Considerando que avaliações como a do Programa Internacional de Avaliação de Estudantes (Pisa) avaliam apenas leitura, matemática e ciências ${ }^{11}$, fica fácil adivinhar quais raízes atrofiar e ramos podar.

Mas o jogo é estratégico e o ataque é cirúrgico. Antes é preciso desqualificar o ensino de História e seus professores, denominando-os ideólogos e doutrinadores reduzir a importância e a presença da disciplina no currículo, negar a relevância social desse conhecimento e sua especificidade, adotar discursos revisionistas e negacionistas, censurar livros didáticos e, xeque-mate, moldar os cursos de formação de professores à floresta calcinada.

Como se não bastasse, internamente à área, em meio às tentativas de sobrevivência, observamos lances de autofagia, como a sugestão de amputação de alguns campos de pesquisa e restrição da disciplina escolar aos conteúdos de

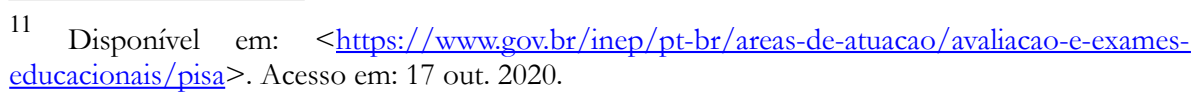


moderna e contemporânea. Emergem indicações de que eleger uma determinada referência teórica, numa única teoria da História, seria a tábua de salvação, a melhor solução para proteger e fortalecer a área forjando consenso sobre seu currículo na Educação Básica. Há, ainda, quem deseje a instituição de um corpo conceitual mínimo que seja critério de validação do trabalho do profissional de ensino de história. Tais proposições, ao nosso ver, não tocam e nem são respostas satisfatórias a questões centrais da área em nosso tempo.

Eis nosso ponto. Vivemos tempos paradoxais. Se no campo da História vivemos tempos de encantamento que provém do crescimento e expansão da pesquisa em ensino, que se multiplicam em eventos e publicações, e o recente reconhecimento legal da profissão de historiador, no campo educacional, vivemos a crueza de tempos de implementação de políticas de responsabilização baseadas em resultados aferidos em testes massificados. Elas se combinam com estratégias de premiação e de valorização das chamadas "boas práticas" em troca de premiações e bonificações. Prêmios e bônus são novas moedas de troca em substituição à valorização da carreira e do piso salarial. Enquanto isso, a profissão docente é precarizada e a etapa de formação inicial aligeirada por um modelo que prioriza o praticismo pedagógico, atrofiando os campos específicos da área de conhecimento histórico e da pesquisa, cindindo a própria dimensão utópica do fazer docente em História.

Entre o chão que treme sob nossos pés e certo triunfo inebriante da área, o fato é que se nada for feito com urgência, os cursos de graduação em história, tal qual os conhecemos, estão com os dias contados. Mas não será surpresa se alguns formadores de professores de História preferirem deixar o barco correr. E nessa janela de oportunidade sacramentarem a divisão intelectual do trabalho entre aqueles que se dedicam a formar historiadores, que produzem o saber histórico, e aqueles que formam uma massa docente empenhada em sua difusão, lógico que com as novidades mais frescas da moda pedagógica ou teórica e os mais recentes aparatos das novas tecnologias. Entendemos que se nada for feito com urgência, a disciplina de História no Ensino Médio será apenas um componente curricular liquefeito e diluído na área de Ciências Humanas e Sociais Aplicadas. Mas há quem pense ser melhor aproveitar os ventos da interdisciplinaridade - sem disciplinas, o que constitui um paradoxo - e se aventurar em novos desenhos curriculares.

Desse modo, extirpando ou reduzindo o conhecimento histórico da educação básica e transformando o curso de formação de professores em algo diluído e anódino, retira-se dos alunos a possibilidade de ressignificar o presentismo em que vivemos. $\mathrm{E}$ isso atinge principalmente os alunos da classe traba- 
lhadora e alunos-trabalhadores que serão privados da possibilidade de pensar historicamente, ficando condenados ao mundo do trabalho e à ausência de horizonte de expectativa (KOSELLECK, 2011). A esse grupo de estudantes não se aplicará o que Bittencourt entende ser a contribuição do ensino de história: "libertar o indivíduo do tempo presente e da imobilidade diante dos acontecimentos, para que possa entender que cidadania não se constitui em direitos concedidos pelo poder instituído, mas tem sido obtida em lutas constantes e em suas diversas dimensões." (1997, p. 20)

Haverá um achatamento do tempo, condenando essa parcela de alunos ao eterno presente, sem passado e sem futuro. Isso, obviamente, não ocorrerá (ao menos não com a mesma intensidade) com os filhos das classes dominantes, cujos pais não renunciarão à zelosa formação com sólido conhecimento histórico, além do artístico, de línguas, filosófico, sociológico etc. Confirma-se assim a hipótese de um ensino precário para o precariado.

Pode parecer meio drástico e algo pessimista, mas é que a situação é inteira drástica, e o pessimismo fermento de resistências e utopias.

\section{Referências}

ALMEIDA NETO. Antonio Simplício de. Representações utópicas no ensino de História. São Paulo: Editora Unifesp, 2011.

BARROS, Daniel. Educação não é um fim em si mesma e deve se aproximar do mercado de trabalho - maior interação propiciada pelo Novo Ensino Médio ampliará o horizonte de carreiras para jovens de baixa renda. Folha de São Paulo, 29/agosto/2020. Disponível em: < https://www1.folha.uol.com.br/ilustrissima/2020/08/educacao-nao-e-um-fim-em-si-mesma-e-deve-se-aproximardo-mercado-de-trabalho.shtml>. Acesso em: 02 nov. 2020.

BASE NACIONAL COMUM CURRICULAR - Ensino Médio. Brasília, MEC/CONSED/UNDIME, 2018. Disponível em: $<$ http://

portal.mec.gov.br/conselho-nacional-de-educacao/base-nacional-comum-curricular-bncc-etapa-ensino-medio >. Acesso em: 02 nov. 2020.

BITTENCOURT, Circe. (org). O saber histórico na sala de aula. SP: Contexto, 1997.

FERREIRA, Angela Ribeiro. Entre as práticas das teorias e vice-versa - a prática de ensino como componente curricular nas licenciaturas em história no Brasil após 2002. (Tese). 2015. Universidade Estadual de Ponta Grossa, 2015. 
Disponível em: < http://tede2.uepg.br/ispui/handle/prefix/1185 $>$. Acesso em: 10 out. 2020 .

GUIA DE IMPLEMENTAÇÃO DO NOVO ENSINO MÉDIO. BRASÍLIA. MEC. Disponível em: $<$ http://novoensinomedio.mec.gov.br/\#!/guia $>$. Acesso em: 06 out. 2020.

KOSELLECK, Reinhart. Futuro Passado: contribuição à semântica dos tempos históricos. Rio de Janeiro: Contrapondo/Puc-Rio, 2011.

NORA, Pierre. Entre a memória e a história: o problema dos lugares. In: Projeto História. SP: PUCSP, 1993.

Prefeitura do Rio compara escola a fábrica e gera críticas no Facebook. UOL Educação, 2020. Disponível em: < https://educacao.uol.com.br/noticias/ 2014/12/09/prefeitura-do-rio-compara-escola-a-fabrica-e-gera-criticas-no-facebook.htm>. Acesso em: 31 out. 2020.

PISA. Programa Internacional de Avaliação de Estudantes. Brasília, MEC, 2020. Disponível em: < https://www.gov.br/inep/pt-br/areas-de-atuacao/avaliacao-e-exames-educacionais/pisa >. Acesso em: 17 out. 2020.

RESOLUÇÃO CNE/CP Nº 2, DE 20 DE DEZEMBRO DE 2019. Diretrizes Curriculares Nacionais para a Formação Inicial de Professores para a Educação Básica e institui a Base Nacional Comum para a Formação Inicial de Professores da Educação Básica (BNC-Formação). Brasília, MEC, 2020. Disponível em: < http://portal.mec.gov.br/docman/dezembro-2019-pdf/135951-rcp002-19/ file\#: : $\operatorname{text}=\mathrm{Par} \% \mathrm{C} 3 \% \mathrm{~A} 1 \mathrm{grafo} \% 20 \% \mathrm{C} 3 \% \mathrm{BAnico}$ -, As $\% 20$ Diretrizes $\% 20 \mathrm{Cur}-$ riculares $\% 20$ Nacionais $\% 20$ para $\% 20 \mathrm{a} \% 20 \mathrm{Forma} \% \mathrm{C} 3 \% \mathrm{~A} 7 \% \mathrm{C} 3 \% \mathrm{~A} 3 \mathrm{O} \% 20$ Inicial $\% 20 \mathrm{em} \% 20 \mathrm{~N} \% \mathrm{C} 3 \%$ ADvel,Art>. Acesso em: 02 nov. 2020.

RESOLUÇÃO Nº 2, DE $1^{\circ}$ DE JULHO DE 2015. Diretrizes Curriculares Nacionais para a formação inicial em nível superior. Brasília, MEC/CNE, 2015. Disponível em < http://portal.mec.gov.br/docman/agosto-2017-pdf/70431res-cne-cp-002-03072015-pdf/file. $>$ Acesso em: 02 nov. 2020.

São Paulo é o primeiro estado do Brasil e adotar o currículo do Ensino Médio. Portal do Governo. São Paulo (estado), 2020. In: Disponível em: $<\underline{\text { https: } / /}$ www.saopaulo.sp.gov.br/ultimas-noticias/sp-e-o-primeiro-estado-do-brasil-aaprovar-o-curriculo-do-ensino-medio/\#: : text $=$ Estrutura $\% 20 \mathrm{do} \% 20$ curr $\% \mathrm{C} 3 \% \mathrm{AD}$ culo, $\mathrm{s} \% \mathrm{C} 3 \% \mathrm{~A} 3 \mathrm{o} \% 20$ referentes $\% 20$ aos $\% 20$ itiner $\% \mathrm{C} 3 \% \mathrm{~A} 1$ rios \%20formativos >. Acesso em: 06 out. 2020. 
Standing, Guy. O precariado: a nova classe perigosa. Belo Horizonte: Autêntica, 2014. 